\title{
Studies on the Gall Characteristics of Dryocosmus kuriphilus in Chestnut Genotypes in Yalova and Bursa Provinces of Turkey
}

\author{
Nimet S. GENÇER ${ }^{1 *}$, Cevriye MERT ${ }^{2}$ \\ ${ }^{1}$ University of Uludag, Faculty of Agriculture, Department of Plant Protection, 16059 Görükle Campus, Nilüfer, Bursa, \\ Turkey; nsgencer@uludag.edu.tr (*orrespondingauthor) \\ ${ }^{2}$ University of Uludag, Faculty of Agriculture, Department of Horticulture, 16059 Görükle Campus, Nilüfer, Bursa, \\ Turkey; cevmert@uludag.edu.tr
}

\begin{abstract}
The Asian chestnut gall wasp Dryocosmus kuriphilus is a global pest of chestnut (Castanea spp.). It has been spreading in Turkey's forests and orchards since 2014. This pest imposes a big threat to the Turkish chestnut industry, which is among the top producers in the world. Its gall morphology has been related to pest pressure and host cultivar, thus eventually modulating plant damage with heavy impact on growth and fruit production. We compared gall characters (position on plant organ, ratios, dimensions, volumes, number of larval chambers) in wild Castanea sativa, two local cultivars and a Euro Japanese hybrid. Overall, leaf galls were more common (55.36\%), followed by the stem (19.6\%) and leaf stipule galls (15.29\%). The mean number of chamber and volume value of gall types were $1.52-5.93$ and $0.43-2.15 \mathrm{~cm}^{3}$, respectively. The highest values were observed in 'stem gall'. The more gall formation was observed in the wild chestnut trees and 'Marigoule' than the other local varieties.
\end{abstract}

Keywords: chambers; Cynipidae; gall types; gall wasp; Hymenoptera

\section{Introduction}

Turkey is one of the main chestnut producing countries in the world. Annual nut production is about 60,000 tons. In addition chestnut populations are widely spread in the coastal regions e.g. Black Sea, Marmara, and Aegean Sea Regions. These areas have generous populations of Castanea sativa Mill., with approximately 2,5 million trees. Therefore, a wide range of genetic variability existed in the populations. Genetic variability exists in nut and tree characteristics, yield, and probably pest and disease resistance, as well as other agricultural traits. However, some lethal diseases of chestnut e.g. ink disease (caused by Phytophthora sp.), present since 1940, and later chestnut blight disease (caused by Cryphonectria parasitica, present since 1968) had seriously damaged the chestnut grooves and the annual nut production has decreased significantly, especially in Marmara and Black Sea Regions. Damage has been observed recently in the Aegean Region due to the harmful effects of chestnut blight (Soylu and Mert, 2009).

The Asian chestnut gall wasp Dryocosmus kuriphilus Yasumatsu (Hymenoptera: Cynipidae) is a serious invasive pest of chestnut globally. The wasp is native to China, but the pest was accidentally introduced first to Japan and Korea and then to the U.S.A. (Shiraga, 1951; Cho and Lee, 1963; Payne et al., 1975; Moriya et al., 1989). In 2002, the wasp was also detected in Europe (Brussino et al., 2002; Seljak, 2006; EPPO, 2007; EPPO, 2010a; EPPO, 2010b; Matošević et al., 2010; Michaelakis et al., 2016). In Turkey, it was first reported in Yalova in 2014 and later in Bursa (Çetin et al., 2014).

Dryocosmus kuriphilus is univoltine and reproduces parthenogenetically. During the oviposition period from June to July, females emerge and lay eggs in the buds of chestnut trees (Cho and Lee, 1963). During spring, at the time of bud burst, galls were seen on new chestnut organs (Cooper and Rieske, 2010; Panzavolta et al., 2012; Morath et al., 2015). Galls are unilocular or multilocular, green- or red-colored, and provide larvae with a nutritive supply (Ôtake, 1980; 1989; Cooper and Rieske, 2011). D. kuriphilus gall formation can lead to a marked decrease in fruiting and growth rate, and, in extreme cases, result in plant death (Cho and Lee, 1963; Battisti et al., 2014; Sartor et al., 2015).

The gall is worthy of study for its varying characteristics. It is a product of the interspecific association of the plant with the insect, which develops a specific novel structure in response to the insect stimulus (Weis and Abrahamson, 
178

1986; Raman, 2007; 2011). Development of a gall can be seen to include three phases: initiation, growth and maturation (Maresquelle and Mayer, 1965). The gall development starts with the wasp laying eggs in the meristematic tissue of the host plants (Rey, 1992). Galls induced by the Cynipidae, with an outer cortical parenchyma and an inner cavity that contains one to many larval chambers (Hernandez-Soto et al., 2015). Unilocular and multilocular larval chambers containing one $D$. kuriphilus larva per chamber in buds and stem galls (Warmund, 2013). In some studies, it was reported that there were 3.5 larvae per gall (Radócz et al., 2016). Gall size can depend on various factors, such as oviposition strategy, the type of habitat-for example, in highly fragmented habitats (Kato and Hijii, 1993), parasitism pressure (Cooper and Rieske, 2010), the phase of population dynamic (Miyashita et al., 1965) and host plant (Nugnes et al., 2018). Also, gall inhabitants and histology of gall development were studied in different articles (Warmund, 2013; Reale et al., 2016). Additionally, Maltoni et al. (2012), classified the damages caused by galls in chestnut trees.

The objective of the present study was to compare $D$. kuriphilus gall characteristics (number of leaf, stem and stipule galls, gall size, number of larval chambers) in two local chestnut cultivars including the wild chestnut trees and an Euro Japanese hybrid.
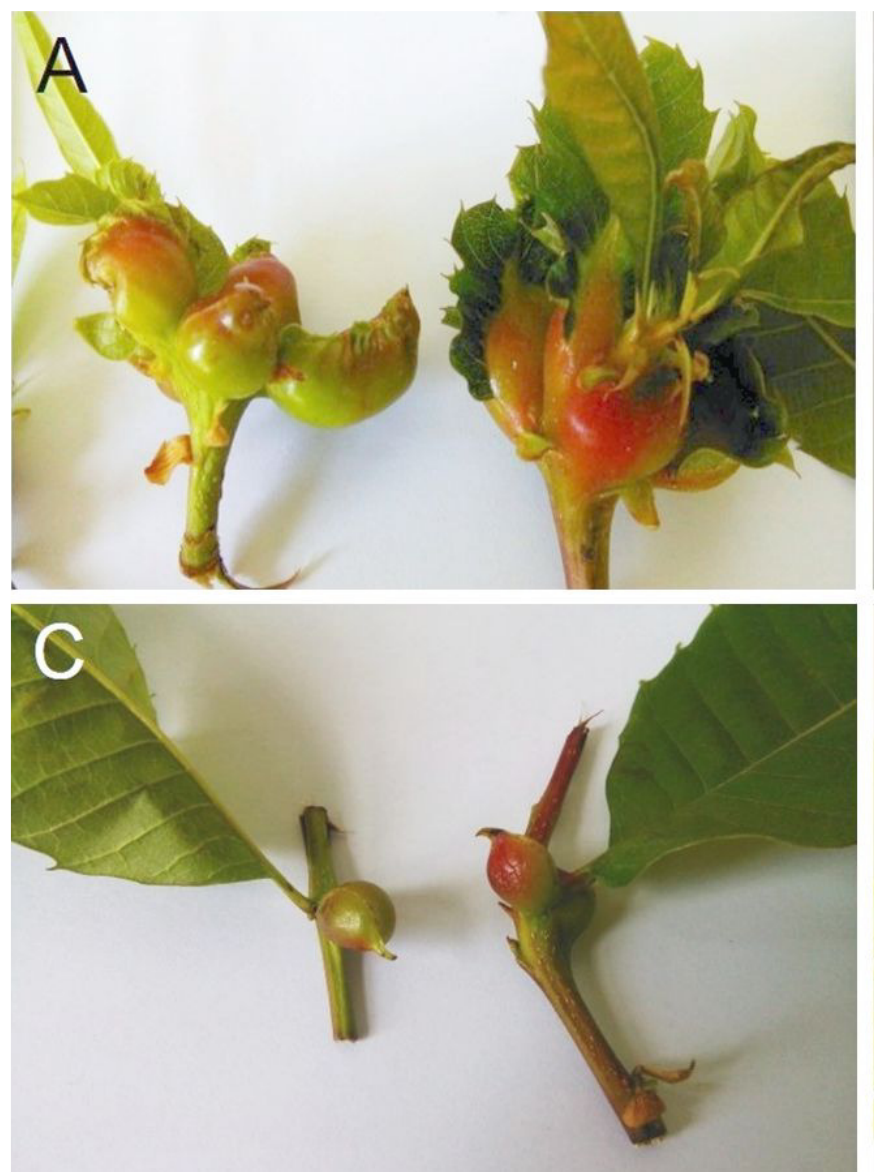

\section{Materials and Methods}

\section{Study site, biological material and procedures}

The investigations were carried out in the commercial chestnut orchards at Yalova (Gacik village) $\left(40^{\circ} .3645^{\prime} \mathrm{N}\right.$, $\left.29^{\circ} .2023^{\prime} \mathrm{E}\right)$ and Bursa (Cumalıkızık village) $\left(40^{\circ} .1021^{\prime} \mathrm{N}\right.$, $29^{\circ} .1016^{\prime}$ E) Provinces of Turkey. Two local (cvs. 'Hacıömer' and 'Bursakestanesi'), one hybrid chestnut cultivar (cv. 'Marigoule') and wild chestnut trees were selected for this study. In spring 2016, 20 pieces of twoyear-old shoots (30-40 cm length) (a total of 100 shoots) were collected from every chestnut variety between April to June at two-week intervals, and the current generation of galls was counted (Panzavolta et al., 2012; Bernardo et al., 2013). Galls were classified into three categories: stem galls (occurring on the chestnut shoot with 2-6 attached leaves), leaf galls (occurring along the leaf lamina) and leaf stipule galls (Fig. 1 A, B, C, D). (Cooper and Rieske, 2010; Panzavolta et al., 2012).

Galls were examined in the laboratory to measure their lengths (-from the shoot-) and width (-at the widest point-) with an automatic micrometer. In each cultivar, 30-50 specimens were measured for every gall type. The volume of each gall was estimated using the volume formula for a cylinder (Panzavolta et al., 2012).

Each gall was then dissected at approximately $2 \mathrm{~mm}$ thickness intervals to record the number of unilocular and

Fig. 1. The galls formed in the chestnuts by Dryocosmus kuriphilus, the stem gall (A), the leaf gall (B), the leaf stipule (C) and the leaf galls, stem gall and leaf stipule gall on young shoot (D) 

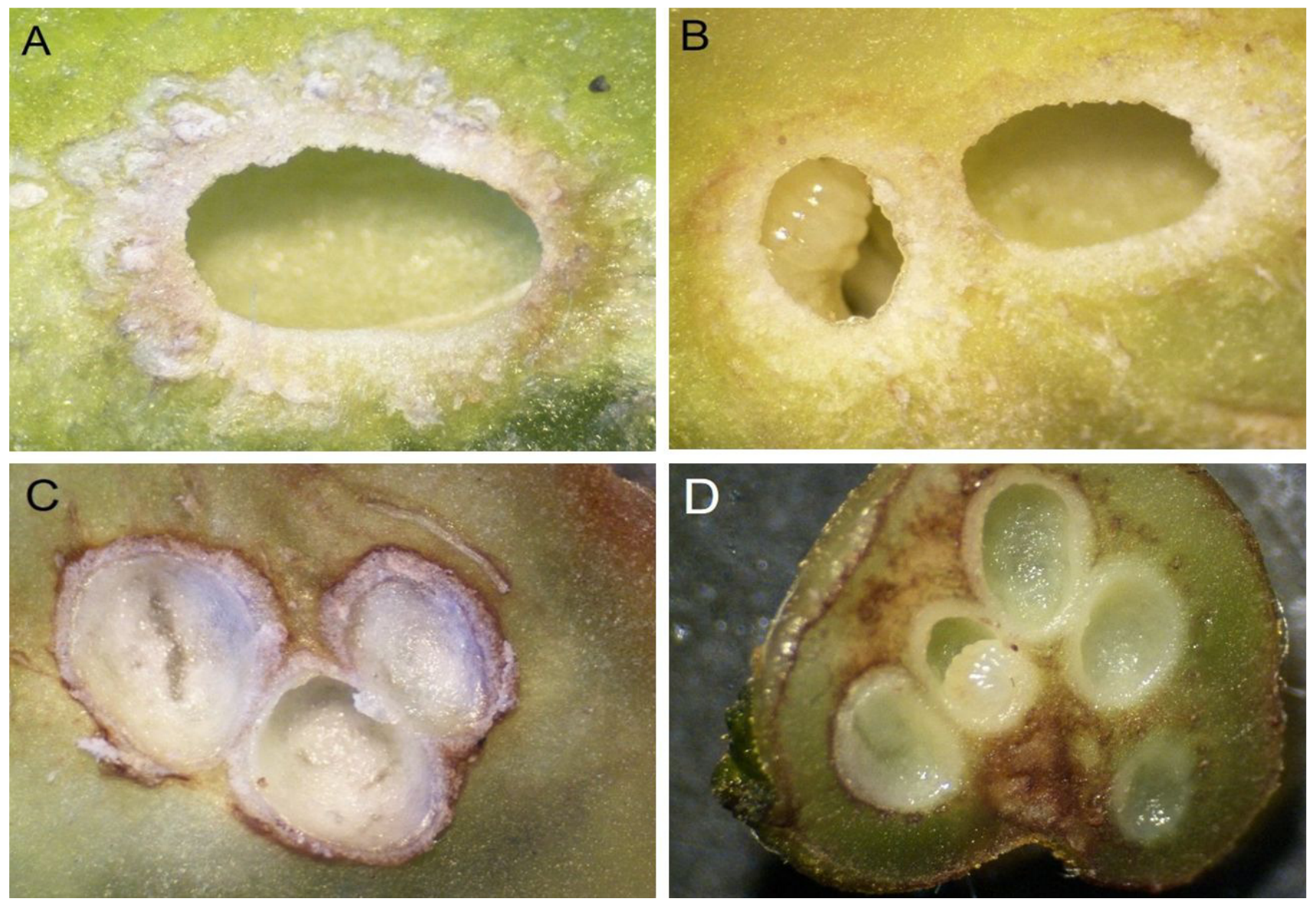

Fig. 2. Unilocular (A) and multilocular (B-D) chambers and D. kuriphilus larvae in gall

multilocular chambers present (Fig. 2 A, B, C, D). A total of 100 stem and leaf galls and 50 leaf stipule galls were used for the dissections. Sections were observed with a stereomicroscope. Number of chambers per leaf, stem and leaf stipule gall were counted.

\section{Statistical analysis}

Statistical comparisons of the mean values were performed using one-way analysis of variance (ANOVA), followed by Duncan's multiple range test $(\mathrm{p}<0.05$ confidence level) using Minitab 17.0 software.

\section{Results and Discussion}

When all genotypes were evaluated, the ratios, average number of chambers, and volume of gall types are given in Table 1. Overall, leaf galls were more common (55.36\%), followed by the stem (19.6\%) and leaf stipule galls (15.29\%). The average number of chamber and volume value of gall types were $1.52-5.93$ and $0.43-2.15 \mathrm{~cm}^{3}$, respectively. The highest values were observed in 'stem gall'.
There were significant differences in gall type ratios in varieties (Fig. 3). Leaf gall ratios in 'Haciömer' (71.28\%) and 'Bursakestanesi' (65.53\%) varieties were higher than 'Wild' (65.53\%) and 'Marigoule' (23.55\%) chestnut varieties (Fig. 3). However, stem gall ratios were high in cv. 'Marigoule' (45.52\%) and wild chestnut trees (31.1\%). The highest leaf stipule galls were observed in cvs. 'Marigoule' (19.94\%), 'Haciömer' (19.28\%) followed by 'Bursakestanesi' (14.13\%) (Fig. 3). Nugnes et al. (2018), stated that the number of stem galls found on the resistant chestnut trees was very low compared to those found on susceptible trees.

The mean number of leaf, stem and leaf stipule gall chambers varied significantly among varieties $(\mathrm{p}<0.05)$ (Fig. 4). Since there were only a few stem galls, measurements were not taken in the 'Haciömer' and 'Bursakestanesi' cultivars. The stem galls have the highest number of chambers, followed by leaf and leaf stipule galls. The leaf galls contained an average of 2.47, 3.34, 3.56 and 4.08 chambers in cvs. 'Bursakestanesi', 'Haciömer', 'Marigoule' and wild trees, respectively. The mean number of stem gall chambers were found to be higher than the other gall types in wild chestnut (4.78) and 'Marigoule'

Table 1. Number of chambers, volume and ration of galls in total

\begin{tabular}{cccc}
\hline Gall type & Gall $(\%)$ & Number of chambers $/$ gall & Gall volume $\left(\mathrm{cm}^{3}\right)$ \\
\hline Stem gall & 19.6 & 5.93 & 2.15 \\
Leaf gall & 55.36 & 3.36 & 1.29 \\
Leaf stipule gall & 15.29 & 1.52 & 0.43 \\
\hline
\end{tabular}


Table 2. Stem, leaf and leaf stipule gall dimensions in chestnut varieties (mean \pm SD)

\begin{tabular}{|c|c|c|c|c|c|c|}
\hline \multirow{2}{*}{ Variety } & \multicolumn{2}{|c|}{ Stem } & \multicolumn{2}{|c|}{ Leaf } & \multicolumn{2}{|c|}{ Leaf Stipule } \\
\hline & Width (mm) & Length $(\mathrm{mm})$ & Width (mm) & Length $(\mathrm{mm})$ & Width (mm) & Length $(\mathrm{mm})$ \\
\hline 'Wild' & $13.01 \pm 2.56$ & $14.86 \pm 2.94$ & $12.15 \pm 2.71 \mathrm{a}$ & $13.91 \pm 3.09 b$ & $8.35 \pm 1.94 \mathrm{a}$ & $9.46 \pm 1.67 b$ \\
\hline 'Haciömer' & & & $10.48 \pm 2.65 b$ & $12.36 \pm 2.87 \mathrm{c}$ & $6.21 \pm 1.60 \mathrm{c}$ & $7.39 \pm 1.62 c$ \\
\hline 'Bursakestanesi' & & & $8.97 \pm 2.24 \mathrm{c}$ & $11.55 \pm 3.68 \mathrm{~d}$ & $7.02 \pm 1.31 \mathrm{bc}$ & $8.42 \pm 1.65 b c$ \\
\hline 'Marigoule' & $13.96 \pm 3.65$ & $12.79 \pm 1.63$ & $10.49 \pm 1.29 b$ & $14.79 \pm 1.35 \mathrm{a}$ & $7.96 \pm 1.09 \mathrm{ab}$ & $10.77 \pm 2.09 \mathrm{a}$ \\
\hline
\end{tabular}

Different letters within the same column indicate significant differences (Duncan test, $\mathrm{p}<0.05$ ).

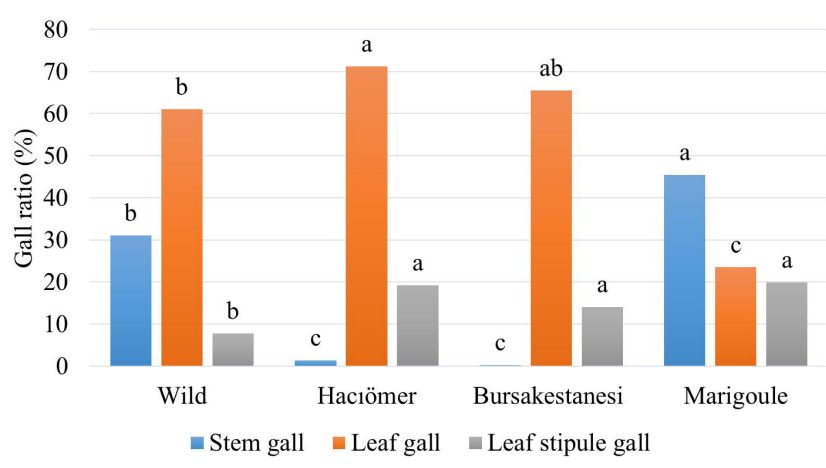

Fig. 3. Ratios of leaf, stem and leaf stipule galls of chestnut varieties

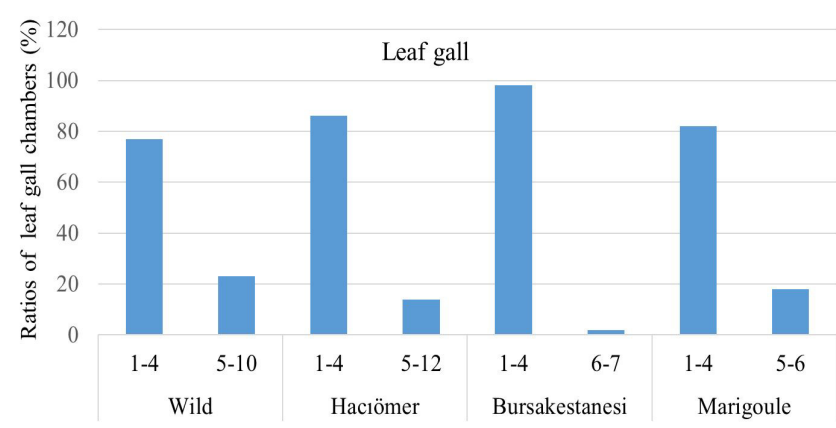

Fig. 5. Ratios of leaf gall chambers of chestnut varieties

variety (7.09). The lowest number of chambers were seen in the leaf stipule galls (Fig. 4). But Panzavolta et al. (2013), stated that a higher mean number of chambers were found on the cultivated chestnuts (3.29) compared to the wild chestnuts (2.99). When all varieties examined, the ratios of leaf galls with $1-4$ chambers were observed to be higher than $5 \leq$ over (Fig. 5). Whereas stem gall ratios with $5 \leq$ over chambers were found to be higher (Fig. 6). There was one D. kuriphilus larva per chamber (Warmund, 2013). Therefore, it was understood that the plants with multicellular gall was preferred by gall wasp. Our results were similar to Panzavolta et al. (2012), who reported that the number of galls in chestnut varieties may be related to wasp population density.

The stem, leaf and leaf stipule gall dimensions varied significantly among varieties $(\mathrm{p}<0.05)$ (Table 2$)$. The largest length $(14.86 \mathrm{~mm})$ of stem galls occurred in the wild trees. The leaf gall width and length ranged between 8.97 and $12.15 \mathrm{~mm}$ and between 11.55 and $14.79 \mathrm{~mm}$ depending on varieties (Table 2). The leaf stipule gall width and length ranged from 6.21 to $8.35 \mathrm{~mm}$ and from 7.39 to $10.77 \mathrm{~mm}$ depending on varieties. Our findings were higher than those obtained by other researchers. The gall diameters ranged between $5-20 \mathrm{~mm}$ in Castanea crenata (Ôtake,

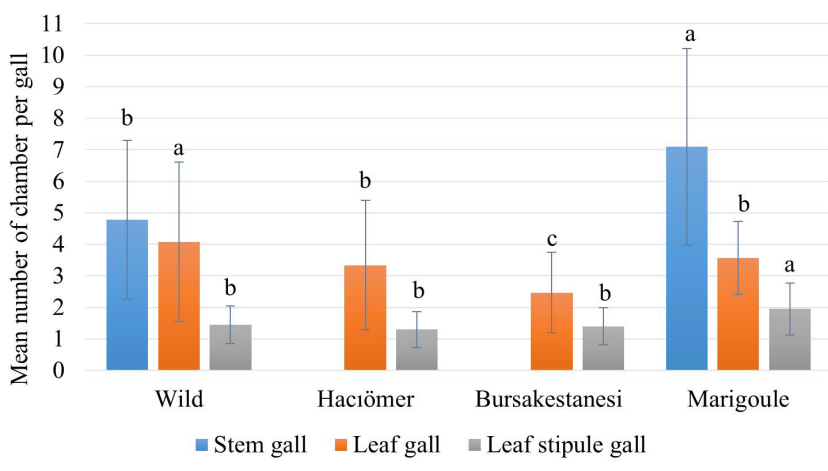

Fig. 4. The mean number of leaf, stem and leaf stipule gall chambers of chestnut varieties

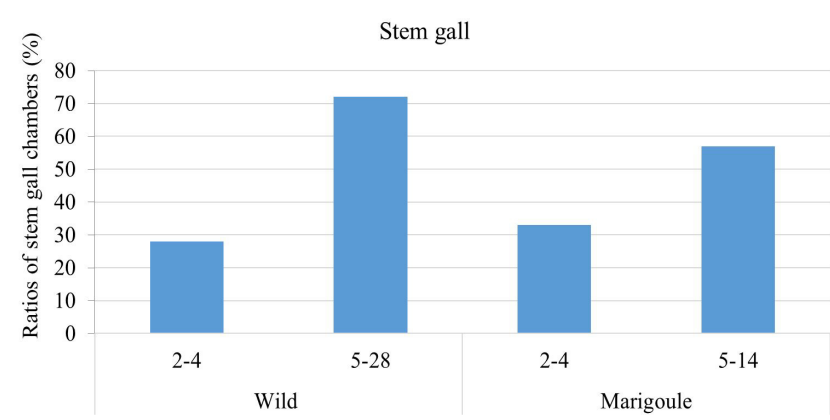

Fig. 6. Ratios of stem gall chambers of chestnut varieties

1980) and 8-15 mm in C. sativa or C. sativa $\times$ C. crenata (Breisch and Streito, 2004).

The volume of leaf, stem and leaf stipule galls of chestnut varieties are shown in Fig. 7. The gall volume varied significantly among varieties $(\mathrm{p}<0.05)$. The leaf and leaf stipule gall volumes of varieties were $0.84-1.80 \mathrm{~cm}^{3}$ and $0.25-0.56 \mathrm{~cm}^{3}$, respectively. Stem galls $\left(2.12-2.19 \mathrm{~cm}^{3}\right)$ had the largest volume.

When all gall types were evaluated together, the 'Marigoule' and wild trees had larger volume galls than the 'Haciömer' and 'Bursakestanesi' cultivars. However, some researchers observed similar values $\left(0.2-2.5 \mathrm{~cm}^{3}\right)$ (Nugnes $e t$ al., 2018) or higher values $\left(0.06-10.46 \mathrm{~cm}^{3}\right)$ (Panzavolta $e t$ al., 2012) than our findings. These differences might be due to various factors such as host plant, population density or oviposition strategy (Miyashita et al., 1965; Kato and Hijii, 1993; Nugnes et al., 2018). When the relationships between gall volume and the chamber numbers were analyzed, there were significant and positive correlation in stem galls $\left(\mathrm{R}^{2}=\right.$ $0.698, \mathrm{p}<0.001)$, and leaf galls $\left(\mathrm{R}^{2}=0.635, \mathrm{p}<0.001\right)$. Similarly, Panzavolta et al. (2012), found a positive correlation between the gall volume and the number of chambers. 


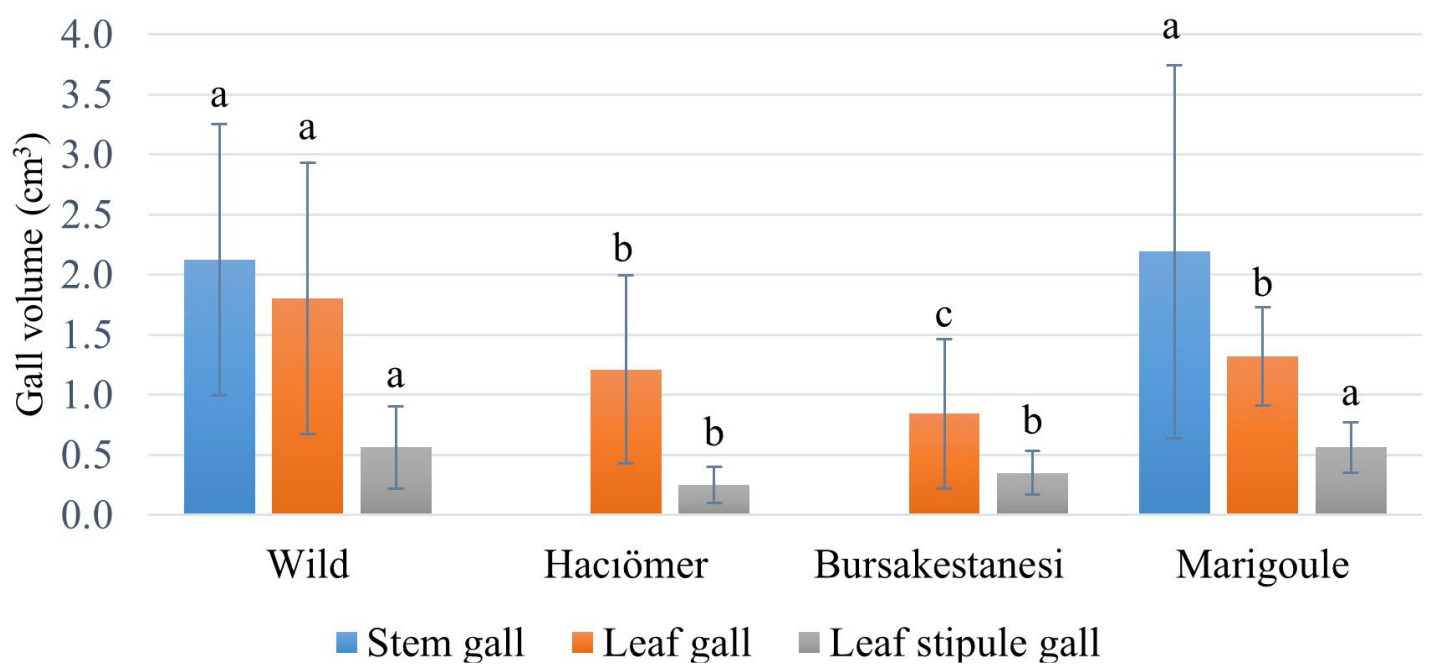

Fig. 7. The stem, leaf and leaf stipule gall volumes of chestnut varieties

\section{Conclusions}

As a result, there were significant differences in terms of gall type ratios, sizes, volumes and chamber numbers depending on the varieties. Leaf gall ratios were considerably higher in the 'Haciömer' (71.28\%) and 'Bursakestanesi' $(65.53 \%)$ variety whereas stem gall ratios were higher in the 'Marigoule' (45.52\%) and wild chestnut trees (31.1\%). Chamber numbers per gall ranged from 2-28, 1-12 and 1-3 in the stem, leaf and leaf stipule gall, respectively. A positive relationship was found between the gall dimensions and the chamber numbers. These results indicated that gall wasp preferred wild chestnut trees and 'Marigoule' variety.

\section{References}

Battisti A, Benvegnù I, Colombari F, Haack RA (2014). Invasion by the chestnut gall wasp in Italy causes significant yield loss in Castanea sativa nut production. Agricultural and Forest Entomology 16:75-79.

Bernardo U, Iodice L, Sasso R, Valerio A, Tutore VA, CasconeP, GuerrieriE (2013). Biology and monitoring of Dryocosmus kuriphilus on Castanea sativa in Southern Italy. Agricultural and Forest Entomology 15:65-76.

Breisch H, Streito JC (2004). Le cynips du châtaignier: un nouveau fléau pour l'Europe. Infos CTIFL (Centre Technique Interprofessionnel des Fruitset Légumes) 204:3437.

Brussino G, Bosio G, Baudino M, Giordano R, RamelloF, Melika G (2002). Pericoloso insetto esotico per il castagno europeo. Informatore Agrario 58:59-61.

Cho DY, Lee SO (1963). Ecological studies on the chestnut gall wasp, Dryocosmus kuriphilus Yasumatsu, and observation on the damages of the chestnut trees by its insect. Korean Journal of Plant Protection 2:4754

Cooper WR, Rieske LK (2010). Gall structure affects ecological association of Dryocosmus kuriphilus (Hymenoptera: Cynipidae). Environmental Entomology 39:787-797.

Cooper WR, Rieske LK (2011). A native and an introduced parasitoid utilize an exotic gallmaker host. BioControl 56:725-734.
Çetin G, Orman E, Polat Z (2014). First record of the oriental chestnut gall wasp, Dryocosmus kuriphilus Yasumatsu (Hymenoptera: Cynipidae) in Turkey. Plant Protection Bulletin 54(4):303-309.

EPPO (2007). European and Mediterranean Plant Protection Organization (EPPO). Dryocosmus kuriphilus Found in the South of France (Alpes Maritimes). OEPP/EPPO ReportingService, 5 (2007/086).

EPPO (2010a). European and Mediterranean Plant Protection Organization (EPPO). First Report of Dryocosmus kuriphilus in the Netherlands. OEPP/EPPO ReportingService, 8(2010/134).

EPPO (2010b). European and Mediterranean Plant Protection Organization (EPPO). Incursion of Dryocosmus kuriphilus in Hungary. OEPP/EPPO Reporting service, 8 (2010/135).

Hernández-Soto P, Lara-Flores M, Agredano-Moreno L, Jiménez-García LF, Cuevas-Reyes P, Oyama K (2015). Developmental morphology of budgalls induced on the vegetative meristems of Quercus castanea by Amphibolips michoacaensis (Hymenoptera: Cynipidae). Botanical Sciences 93(4):1-9.

Kato K, Hijii N (1993). Optimal clutch size of the chestnut gall wasp, Dryocosmus kuriphilus Yasumatsu (Hymenoptera: Cynipidae). Researches on Population Ecology 35:1-14.

Maresquelle HJ, Meyer J (1965). Physiologie et morphogenèse des galles d'origine animale (zoocécides). In: Ruhland W, Ashby E, Bonner J, Geiger-Huber M, James WO, Lang A, Müller D, Stålfelt MG (Eds). Handbuch der Pflanzenphysiologie, Band XV: Differenzierung und Entwicklung, Teil 2. Springer-Verlang, Berlin pp 280-329.

Maltoni A, Mariotti B, Tani A(2012). Case study of a new method for the classification and analysis of Dryocosmus kuriphilus Yasumatsu damage toyoung chestnut sprouts. iForest-Biogeosciences and Forestry 5.2:50.

Matošević D, Pernek M,Hrašovec B (2010). First record of oriental chestnut gall wasp (Dryocosmus kuriphilus) in Croatia. Prethodno Priop Cenje 9(10):497-502.

Michaelakis A, Papachristos DP, Chytas DA, Antonopoulou PD, Milonas PG, Avtzis DN (2016). First record of Dryocosmus kuriphilus in Greece. Bulletin OEPP/EPPO Bulletin 46(2):290-294. 
182

Miyashita K, Itô Y, Nakamura K, Nakamura M, Kondo M (1965). Population dynamics of the chestnut gall-wasp, Dryocosmus kuriphilus Yasumatsu (Hymenoptera; Cynipidae). III. Five year observation on population fluctuations. Japanese Journal of Applied Entomology and Zoology 9:42-52.

Morath S, Fielding N, Tilbury C, Jones B (2015). Features oriental chestnut gall wasp news of a recent unwelcome discovery and how 'citizen science' can play an important role in surveying and identification. Quarterly Journal of Forestry 109(4):253-258.

Moriya S, Inoue K, Mabuchi M (1989). The use of Torymus sinensis to control chestnut gall-wasp, Dryocosmus kuriphilus, in Japan. Technical Bulletin of the Food and Fertilizer Technology Center 118:1-12.

Nugnes F, Gualtieri L, Bonsignore CP, Parillo R, Annarumma R, Griffo R, Bernardo U (2018). Resistance of a local ecotype of Castanea sativa to Dryocosmus kuriphilus (Hymenoptera: Cynipidae) in Southern Italy. Forests 9(94):1-12.

Ôtake A (1980). Chestnut gall wasp, Dryocosmus kuriphilus Yasumatsu (Hymenoptera: Cynipidae): a preliminary study on trend of adult emergence and some other ecological aspects related to the final stage of itslife cycle. Applied Entomology and Zoology 15:96-105.

Ôtake A (1989). Chestnut gall wasp, Dryocosmus kuriphilus Yasumatsu (Hymenoptera, Cynipidae): Analyses of records on cell contents inside galls and emergence of wasps and parasitoids outside galls. Applied Entomology andZoology 24:193-201.

Panzavolta T, Bracalini M, Croci F, Campani C, Bartoletti T, Miniati G, BenedettelliS, Tiberi R(2012). Asian chestnut gall wasp in Tuscany: gall characteristics, egg distribution and chestnut cultivar susceptibility. Agricultural and Forest Entomology 14:139-145.

Panzavolta T, Bernardo U, Bracalini M, Cascone P, Croci F, Gebiola M, Iodice L, Tiberi R, GuerrieriE (2013). Native parasitoids associated with Dryocosmus kuriphilus in Tuscany, Italy. Bulletin of Insectology 66 (2):195-201.

Payne JA, Menke AS, Schroeder PM (1975). Dryocosmus kuriphilus Yasumatsu (Hymenoptera: Cynipidae), an oriental chestnut gall wasp in North America. U.S. Department of Agriculture Cooperative Economic Insect Report 25:903-905.
Radócz L, Szilágyi A, Nagy M, Kovács G, Melika G (2016). Asian sweet chestnut gall wasp, Dryocosmus kuriphilus (Hymenoptera, Cynipidae): first record for Romania. North-Western Journal of Zoology 12(1):201-204.

Raman A (2007). Insect-induced plant galls of India: unresolved questions. Current Science 92:748-757.

Raman A (2011). Morphogenesis of insect-induced plant galls: facts and questions. Flora 206:517-533.

Reale L, Tedeschini E, Rondoni G, Ricci C, Bin F, Frenguelli G, Ferranti F (2016). Histological investigation on gall development induced by a worldwide invasive pest, Dryocosmus kuriphilus, on Castanea sativa. Plant Biosystems 150(1):35-42.

Rey LA (1992). Developmental morphology of two types of hymenopterous galls. In: Shorthouse JD, Rohfritsch O (Eds). Biology of Insect-Induced Galls, Oxford University Press, Oxford pp 87-101.

Sartor C, Dini F, Marinoni DT, Mellano MG, Beccaro GL, Alma A, Quacchia A, Botta R (2015). Impact of the Asian wasp Dryocosmus kuriphilus (Yasumatsu) on cultivated chestnut: Yield loss and cultivar susceptibility. Scientia Horticulturae 197:454-460.

Seljak G (2006). Oriental chestnut gall wasp - a new major threat to sweet chestnut. SAD, Revija za Sadjarstvo, Vinogradnistvo in Vinarstvo 17:35.

Shiraga T (1951). Chestnutgall wasps and the control. Journal of Agriculture and Horticulture 26:167-170.

Soylu A, Mert C (2009). The future of chestnut breeding work in Turkey. Acta Horticulturae 815:27-32.

Warmund MR (2013). Dryocosmus kuriphilus-induced chestnut galls and their inhabitants. HortScience 48(8):969-974.

Weis AE, Abrahamson WG (1986). Evolution of host plant manipulation by gall makers: ecological and genetic factors in the Solidago-Eurosta system. The American Naturalist 127:681-695. 